\title{
FEASIBILITY OF USING OSCILLATORY CATALYTIC OXIDATION PHENOMENON FOR SELECTIVE CARBON MONOXIDE SENSING
}

\author{
HEIKKI TORVELA \\ Microelectronics Laboratory, University of Oulu, SF-90570 OULU, FINLAND.
}

\begin{abstract}
Tin dioxide based sensors with different additives were constructed and tested in air environment containing carbon monoxide. Conductance oscillations were observed in samples containing palladium but not in those without. Oscillations occurred at temperatures ranging from $150^{\circ} \mathrm{C}$ to $320^{\circ} \mathrm{C}$. Within this temperature region the range of $\mathrm{CO}$ concentrations at which oscillations appeared became higher as the test temperature increased. The lowest $\mathrm{CO}$ concentration at which oscillations were observed was $200 \mathrm{ppm}$ and the highest $10000 \mathrm{ppm}$.

By comparing sensor responses obtained in synthetic and ambient air it was concluded that water vapour has a major influence on oscillations and increases the frequency. The ranges of $\mathrm{CO}$ concentrations in which oscillations occurred at different temperatures, however, remained roughly the same in both environments. It was also noticed that processing conditions had an influence on the oscillatory response characteristics of the sensors.
\end{abstract}

\section{INTRODUCTION}

Small amounts of $\mathrm{CO}$ together with oxygen have been found to cause conductance oscillations in tin dioxide based semiconductor gas sensors ${ }^{1,2,3}$. These oscillations have been observed when sensors contain noble metal catalysts. The domain of appearance has been in the temperature range of $150^{\circ} \mathrm{C}$ to $300^{\circ} \mathrm{C}$ and in the $\mathrm{CO}$ concentration range of 500 to 8000 ppm.

It has also been noted that at any particular temperature the period and the amplitude of the oscillations depend on $\mathrm{CO}$ concentration. These observations have evoked the question as to whether this phenomenon could be put to use as the operation principle of a selective $\mathrm{CO}$ sensor.

In this study the applicability and reproducibility of $\mathrm{SnO}_{2}$-based sensors is evaluated so as to establish the feasibility of using the oscillatory oxidation phenomenon as the basis of $\mathrm{CO}$ sensing. For this purpose sensors of different compositions were manufactured, some with addition of palladium and some without. The sensors were fabricated using thick film technology. The base material was $\mathrm{SnO}_{2}$ to which $\mathrm{Pd}$ was added as the catalyst.

Oscillation characteristics of these sensors were investigated. Comparisons were made between sensors with the same composition but sintered at different temperatures. The ranges of $\mathrm{CO}$ concentration in which oscillations occurred at different sensor operating temperatures were determined. Measurements were carried out in synthetic and ambient air environments so as to evaluate the importance of the environment on the oscillation response of the sensors to $\mathrm{CO}$.

The oscillations observed san be attributed to the oscillatory catalytic oxidation of CO. This aspect is discussed in terms of $\mathrm{CO}$ oxidation on supported noble metal catalyst.

\section{EXPERIMENTAL PROCEDURE}

The constituents of the sensing material were mixed with organic component to form a paste capable of being screen printed. One composition was similar to that used by $\mathrm{S}$. Kanefusa et $\mathrm{al}^{2}$ which was $\mathrm{SnO}_{2}$ containing $1 \mathrm{wt} \% \mathrm{PdCl}_{2}, 1 \mathrm{wt} \% \mathrm{Mg}\left(\mathrm{NO}_{3}\right)_{2}, 5 \mathrm{wt} \% \mathrm{ThO}_{2}$ and $2 \mathrm{wt} \%$ 
$\mathrm{SiO}_{2}$. Two other compositions were similar except that one of them was prepared without $\mathrm{ThO}_{2}$ and the other without $\mathrm{PdCl}_{2}$. The fourth composition contained only $\mathrm{SnO}_{2}$ with $2 \mathrm{wt} \%$ $\mathrm{SiO}_{2}$.

Sensors were fabricated using thick film technology ${ }^{4}$. The final sintering of the gas sensitive layer was carried out in a belt furnace at peak temperatures of $600^{\circ} \mathrm{C}$ and $850^{\circ} \mathrm{C}$. The sintering time was $15 \mathrm{~min}$.

The current responses of the sensors were measured at temperatures ranging from $150^{\circ} \mathrm{C}$ to $320^{\circ} \mathrm{C}$. In the case where temperature control was accomplished by a platinum resistor printed on the reverse side of the substrate supporting the sensor, the sensors were placed in a glass chamber. A temperature-controlled oven with a $\mathrm{CrNi}-\mathrm{Ni}$ thermocouple was used to calibrate the heating resistors. This oven was also used in some response measurements to ensure identical thermal conditions for the samples being compared.

The concentration of the gas was adjusted by mixing $1 \mathrm{vol} \%$ of $\mathrm{CO}$ in $\mathrm{N}_{2}$ with synthetic air in a gas blender. Synthetic air was used to eliminate the influence of water vapour. The water content in the synthetic air used was around $10 \mathrm{ppm}$. In some experiments normal ambient air from the compressed air delivery system was used so as to evaluate the effect of water vapour.

In order to record responses and oscillations the sensors were connected, 4 to 7 at a time, with a $10 \mathrm{~V}$ DC voltage source and series resistors over which the voltages were recorded.

\section{RESULTS}

Oscillations occurred with sensors containing Pd at temperatures from $150^{\circ} \mathrm{C}$ to $320^{\circ} \mathrm{C}$. Oscillatory behaviour varied widely with gas environment and temperature. Oscillations were found to be statistical in nature. Some variation around the mean value was observed in frequency and amplitude. The oscillatory behaviour seemed to be associated with the presence of Pd since oscillations were not observed when sensors did not contain Pd. Other additives did not greatly influence sensing characteristics. The oscillatory behaviour with and without $\mathrm{ThO}_{2}$ were very similar.

For the sensor sintered at $600^{\circ} \mathrm{C}$ (Sample 1) at the test temperature of $150^{\circ} \mathrm{C}$ the oscillations occurred at the concentration of $200 \mathrm{ppm} \mathrm{CO}$ in synthetic air. The amplitude was $2.5 \mu \mathrm{A}$, or $33 \%$ of the maximum value of the oscillating current, and the period was $\sim 3$ min. For the sensor sintered at $850^{\circ} \mathrm{C}$ (Sample 2) oscillations occurred in the $\mathrm{CO}$ concentration range of $200-400 \mathrm{ppm}$. Only at a CO concentration of $400 \mathrm{ppm}$ were the oscillations regular with a period of $\sim 1 \mathrm{~min}$ and amplitude of $0.6 \mu \mathrm{A}$, or $75 \%$ of the maximum value of the oscillating current. At the temperature of $170^{\circ} \mathrm{C}$ the range where the oscillations occurred was $200-400 \mathrm{ppm}$ of CO in synthetic air with Sample 1 and $400-800 \mathrm{ppm}$ with Sample 2. The periods at $400 \mathrm{ppm}$ of $\mathrm{CO}$ were $\sim 3 \mathrm{~min}$ and $1 \mathrm{~min}$ in Samples 1 and 2, respectively, and amplitudes as indicated in Table I and II. The oscillation waveform of Sample 2 at a CO concentration of $800 \mathrm{ppm}$ is shown in Figure 1, which also shows the cessation of oscillation when the $\mathrm{CO}$ concentration is increased.

Figure 2 shows the current values obtained at $200^{\circ} \mathrm{C}$. The recordings were made at $\mathrm{CO}$ concentrations of 1500 and $2600 \mathrm{ppm}$. The oscillation frequency is lower for the sensor sintered at the lower temperature. The periods at $1500 \mathrm{ppm}$ of $\mathrm{CO}$ were $25 \mathrm{~s}$ and $12 \mathrm{~s}$, respectively, in sensors sintered at $600^{\circ} \mathrm{C}$ and $850^{\circ} \mathrm{C}$. The corresponding amplitudes were 3.8 $\mu \mathrm{A}$ and $3 \mu \mathrm{A}$ or $37 \%$ and $60 \%$ of the maximum value of the oscillating current. The oscillation patterns were different (Figure 2a).

The oscillations ceased at a CO concentration of $\sim 2500 \mathrm{ppm}$ for the sensor sintered at $600^{\circ} \mathrm{C}$. At higher concentrations this sensor showed a steady current reading which increased as the $\mathrm{CO}$ concentration increased. The period of the oscillations of the sensor sintered at $850^{\circ} \mathrm{C}$ was $13 \mathrm{~s}$ at a $\mathrm{CO}$ concentration of $2600 \mathrm{ppm}$ (Figure $2 \mathrm{~b}$ ). For this sensor the oscillations continued up to a CO concentration of $4500 \mathrm{ppm}$ with the period and amplitude 


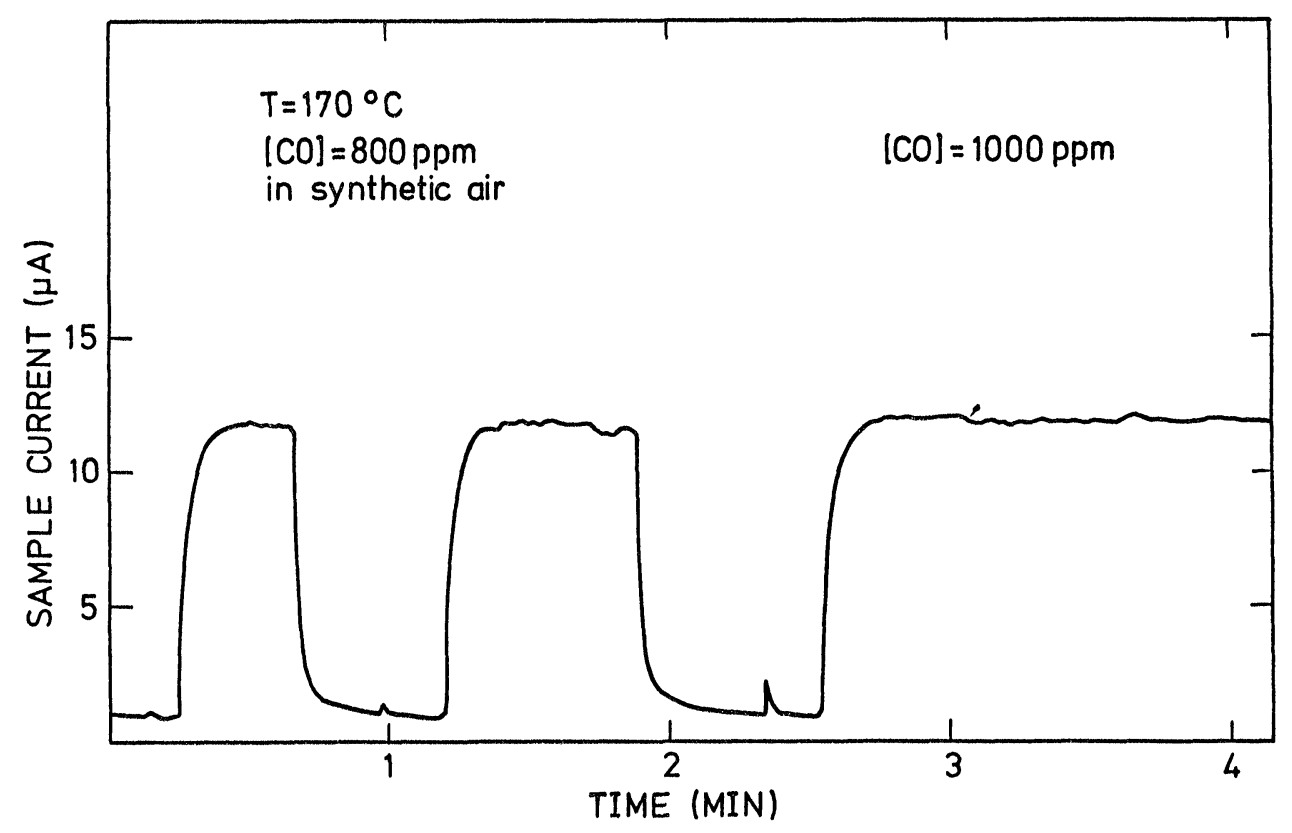

FIGURE 1 Oscillation waveform of sample 2 at $170^{\circ} \mathrm{C}$ in synthetic air. There is a cessation of the oscillation when CO concentration is increased from 800 to $1000 \mathrm{ppm}$.

increasing. This can be seen in Figure 3 which shows the dependence of the oscillation amplitude and period on CO concentration for Samples 1 and 2.

Generally it was noticed that the frequency of the oscillation was higher at higher test temperature (Table III and IV). Also the range of concentrations in which the oscillations appeared became higher with increasing test temperature as shown in Figure 4. For the sensor sintered at $600^{\circ} \mathrm{C}$, for example, oscillations at the test temperatures of $300^{\circ} \mathrm{C}$ and $320^{\circ} \mathrm{C}$ occurred at the $\mathrm{CO}$ concentration of $10000 \mathrm{ppm}$ or $1 \%$, which was the highest concentration available with the experimental set-up. These oscillations were very quick, the shortest period being half a second.

The waveforms of the oscillation varied from a gentle gradient as seen in curve 1 in Figure $2 \mathrm{a}$ to a steep cut-off and onset. Even if the period was long the start-up and decline of the impulse could happen very quickly as is apparent from Figure 1. Between these two types a smooth oscillating waveform appeared, an example of which is shown in Figure $2 b$.

The oscillations recorded when compressed ambient air was the carrier gas had clearly higher frequencies than those with synthetic air as is apparent from Tables III and IV. The amplitudes of the oscillations remained essentially the same. The difference in frequency is believed to be caused by the influence of water vapour. The sensors without Pd addition showed a steady current reading the value of which in ambient air was about twice that in synthetic air.

The values of the test temperatures and the ranges of the concentration of $\mathrm{CO}$ in synthetic air in which oscillations appeared have been outlined in Figure 4 for two types of sensors with the same composition but different final sintering temperatures. It can be concluded that the oscillations tend to occur at lower concentration ranges for the sensor sintered at $600^{\circ} \mathrm{C}$. At all temperatures and concentrations the oscillation period was longer for this sensor compared to that for the sensor sintered at $850^{\circ} \mathrm{C}$ as can be seen from Tables III and IV. 
(a)

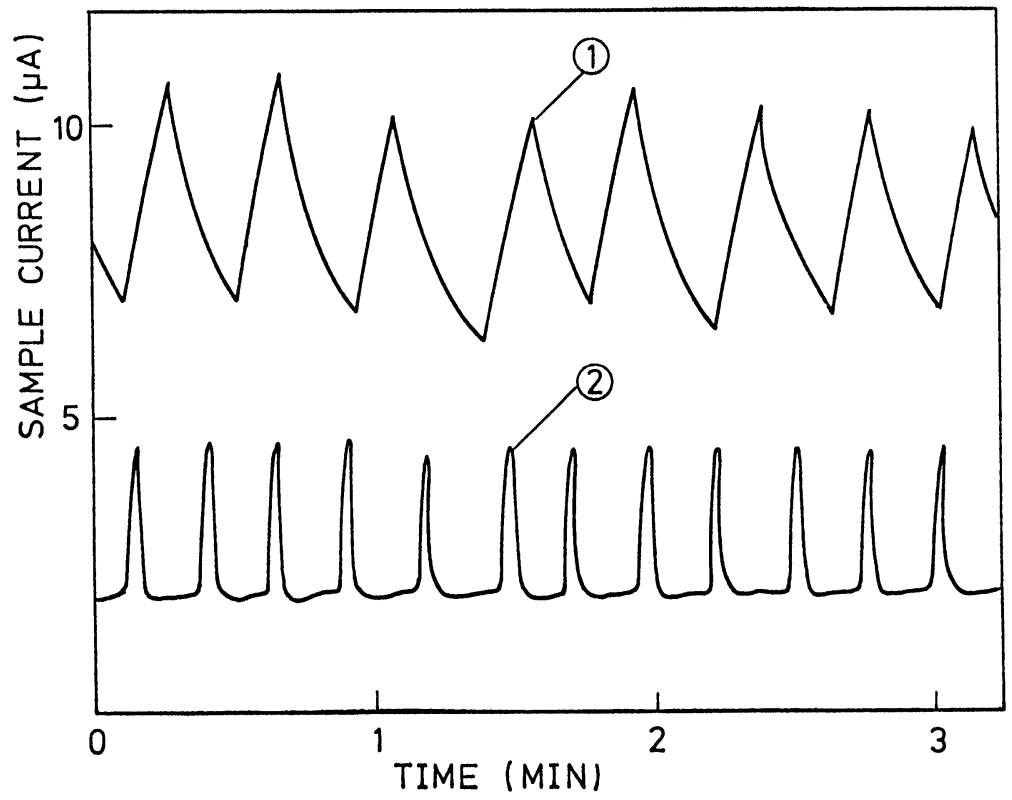

(b)

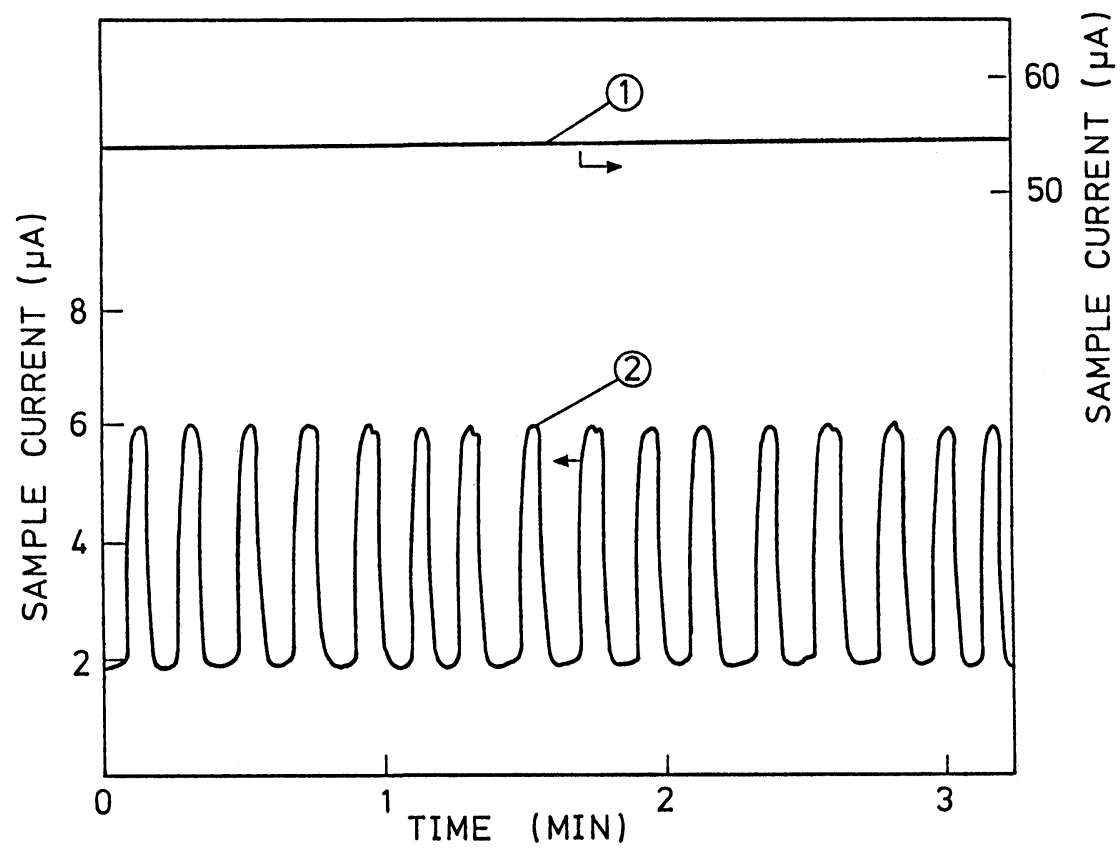

FIGURE 2 Current recordings at $200^{\circ} \mathrm{C}$ of samples sintered at $600^{\circ} \mathrm{C}$ (1) and $850^{\circ} \mathrm{C}$ (2). Carbon monoxide concentration in synthetic air was (a) $1500 \mathrm{ppm}$ and (b) $2600 \mathrm{ppm}$. 
(a)

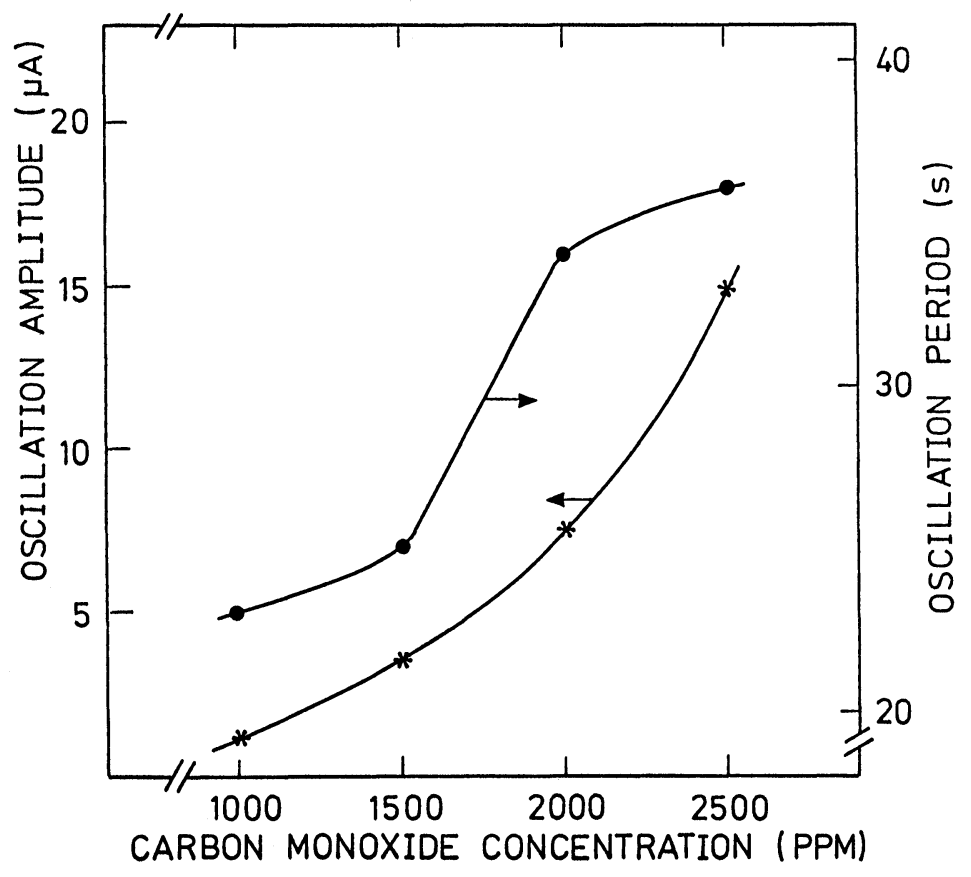

(b)

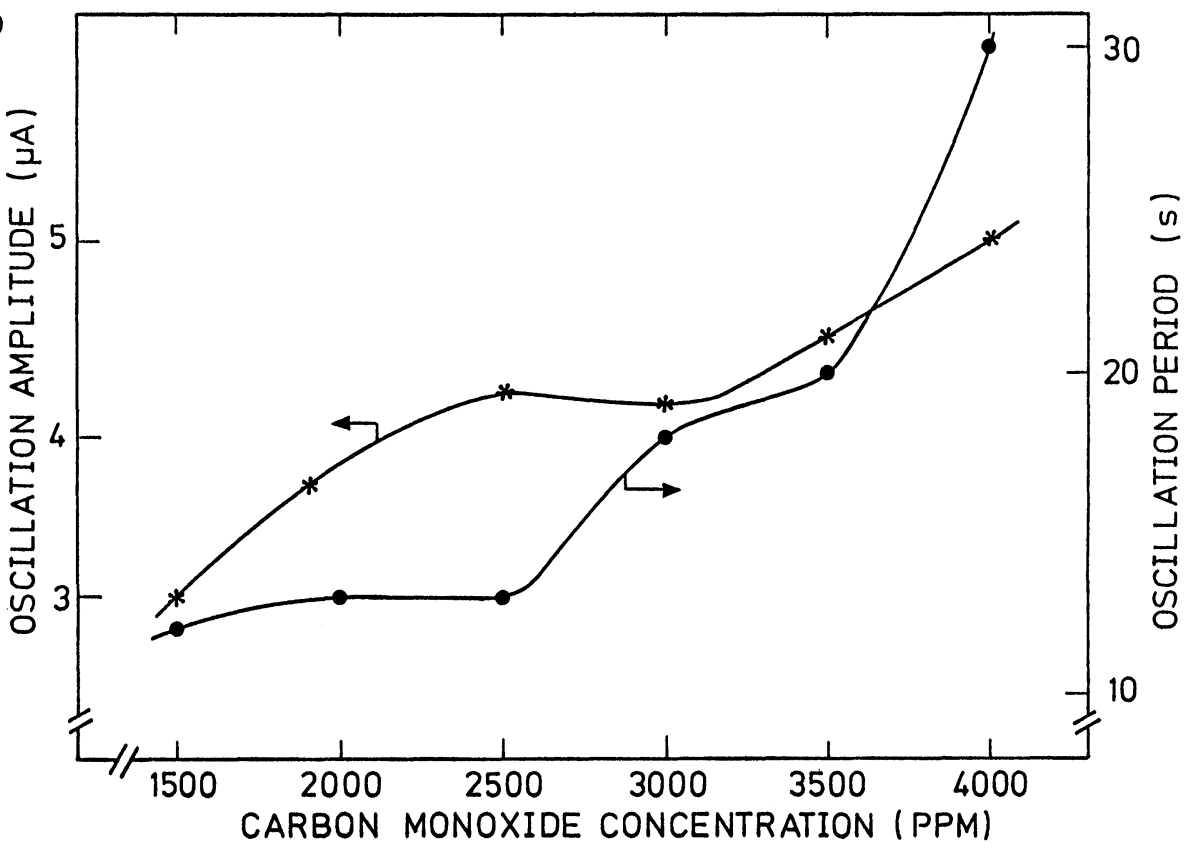

FIGURE 3 The dependence of oscillation amplitude and oscillation period on $\mathrm{CO}$ concentration in synthetic air. Test temperature was $200^{\circ} \mathrm{C}$ and sensors were sintered at (a) $600^{\circ} \mathrm{C}$ and (b) $850^{\circ} \mathrm{C}$. 


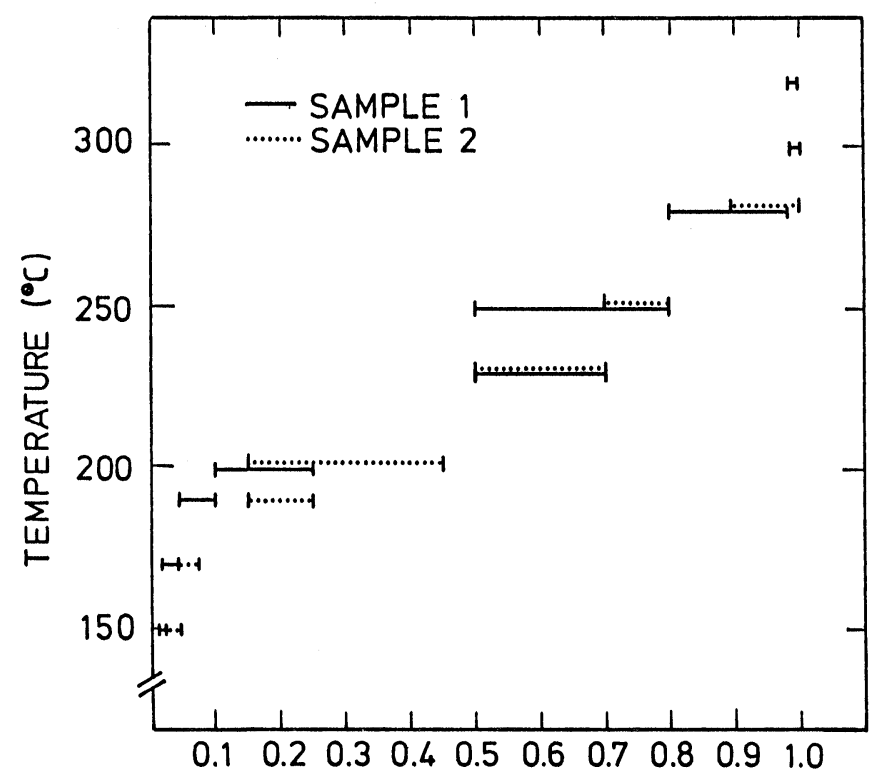

\section{CARBON MONOXIDE CONCENTRATION (\%)}

FIGURE 4 Ranges of $\mathrm{CO}$ concentrations in which oscillations occurred at different temperatures in synthetic air.

TABLE I

Oscillation amplitudes of Sample 1 at different temperatures and $\mathrm{CO}$ concentrations in synthetic air. The amplitude value (AV) and the maximum value (MV) of the oscillating current in $\mu \mathrm{A}$ are given.

\begin{tabular}{|c|c|c|c|c|c|c|c|c|c|c|c|c|c|c|c|c|c|c|}
\hline \multirow{3}{*}{$\begin{array}{l}\text { Conc. } \\
\text { of CO } \\
\text { ppm }\end{array}$} & \multicolumn{18}{|c|}{ Test Temperature ${ }^{\circ} \mathrm{C}$} \\
\hline & \multicolumn{2}{|c|}{150} & \multicolumn{2}{|c|}{170} & \multicolumn{2}{|c|}{190} & \multicolumn{2}{|c|}{200} & \multicolumn{2}{|c|}{230} & \multicolumn{2}{|c|}{250} & \multicolumn{2}{|c|}{280} & \multicolumn{2}{|c|}{300} & \multicolumn{2}{|c|}{320} \\
\hline & AV & MV & $\mathrm{AV}$ & MV & $\mathrm{AV}$ & MV & $\mathrm{AV}$ & MV & AV & MV & AV & MV & AV & MV & AV & MV & AV & MV \\
\hline 200 & 2.5 & 7.5 & 0.7 & 3.2 & & & & & & & & & & & & & & \\
\hline 400 & & & 5.6 & 12.3 & 15.1 & 17.1 & & & & & & & & & & & & \\
\hline 700 & & & & & 0.6 & 3.2 & & & & & & & & & & & & \\
\hline 1000 & & & & & & & 1.2 & 5.2 & & & & & & & & & & \\
\hline 1500 & & & & & & & 3.8 & 10.4 & & & & & & & & & & \\
\hline 2000 & & & & & & & 7.5 & 17.5 & & & & & & & & & & \\
\hline 2500 & & & & & & & 15 & 28 & & & & & & & & & & \\
\hline 3000 & & & & & & & & & & & & & & & & & & \\
\hline 3500 & & & & & & & & & & & & & & & & & & \\
\hline 4000 & & & & & & & & & & & & & & & & & & \\
\hline 4500 & & & & & & & & & & & & & & & & & & \\
\hline 5000 & & & & & & & & & 57 & 65 & 48 & 60 & & & & & & \\
\hline 6000 & & & & & & & & & 82 & 91 & 66 & 80 & & & & & & \\
\hline 7000 & & & & & & & & & 114 & 127 & 96 & 116 & & & & & & \\
\hline 8000 & & & & & & & & & & & 157 & 195 & 6.5 & 65 & & & & \\
\hline 9000 & & & & & & & & & & & & & 198 & 280 & & & & \\
\hline 10000 & & & & & & & & & & & & & 290 & 375 & 150 & 390 & 70 & 260 \\
\hline
\end{tabular}


TABLE II

Oscillation amplitudes of Sample 2 at different temperatures and $C O$ concentrations in synthetic air. The amplitude value (AV) and the maximum value (MV) of the oscillating current in $\mu \mathrm{A}$ are given.

\begin{tabular}{|c|c|c|c|c|c|c|c|c|c|c|c|c|c|c|c|c|c|c|}
\hline \multirow{3}{*}{$\begin{array}{l}\text { Conc. } \\
\text { of CO } \\
\text { ppm }\end{array}$} & \multicolumn{18}{|c|}{ Test Temperature ${ }^{\circ} \mathrm{C}$} \\
\hline & \multicolumn{2}{|c|}{150} & \multicolumn{2}{|c|}{170} & \multicolumn{2}{|c|}{190} & \multicolumn{2}{|c|}{200} & \multicolumn{2}{|c|}{230} & \multicolumn{2}{|c|}{250} & \multicolumn{2}{|c|}{280} & \multicolumn{2}{|c|}{300} & \multicolumn{2}{|c|}{320} \\
\hline & AV & MV & AV & MV & AV & MV & AV & MV & AV & MV & AV & MV & AV & MV & AV & MV & AV & MV \\
\hline 200 & 0.22 & 0.5 & & & & & & & & & & & & & & & & \\
\hline 400 & 0.6 & 0.8 & 4.5 & 7.5 & & & & & & & & & & & & & & \\
\hline 700 & & & 7.5 & 10.5 & & & & & & & & & & & & & & \\
\hline 1000 & & & & & & & & & & & & & & & & & & \\
\hline 1500 & & & & & 2 & 2.65 & 3 & 5 & & & & & & & & & & \\
\hline 2000 & & & & & 2.9 & 3.65 & 3.7 & 5.6 & & & & & & & & & & \\
\hline 2500 & & & & & 3.8 & 4.65 & 4.25 & 6 & & & & & & & & & & \\
\hline 3000 & & & & & & & 4.2 & 5.7 & & & & & & & & & & \\
\hline 3500 & & & & & & & 4.4 & 5.8 & & & & & & & & & & \\
\hline 4000 & & & & & & & 5 & 5.8 & & & & & & & & & & \\
\hline 4500 & & & & & & & 5.1 & 6 & & & & & & & & & & \\
\hline 5000 & & & & & & & & & 5.2 & 8 & & & & & & & & \\
\hline 6000 & & & & & & & & & 7.5 & 10.2 & & & & & & & & \\
\hline 7000 & & & & & & & & & 9.8 & 13.6 & 10.2 & 15 & & & & & & \\
\hline 8000 & & & & & & & & & & & 12 & 16 & & & & & & \\
\hline 9000 & & & & & & & & & & & & & 16 & 31 & & & & \\
\hline 10000 & & & & & & & & & & & & & 39 & 56 & & & & \\
\hline
\end{tabular}

TABLE III

Periods of the oscillations in seconds in Sample 1 at different test temperatures and CO concentrations. Synthetic air (S) and ambient air (A) environments are indicated.

\begin{tabular}{|c|c|c|c|c|c|c|c|c|c|c|c|c|c|c|c|c|c|c|}
\hline \multirow{3}{*}{$\begin{array}{l}\text { Conc. } \\
\text { of CO } \\
\text { ppm }\end{array}$} & \multicolumn{18}{|c|}{ Test Temperature ${ }^{\circ} \mathrm{C}$} \\
\hline & \multicolumn{2}{|c|}{150} & \multicolumn{2}{|c|}{170} & \multicolumn{2}{|c|}{190} & \multicolumn{2}{|c|}{200} & \multicolumn{2}{|c|}{230} & \multicolumn{2}{|c|}{250} & \multicolumn{2}{|c|}{280} & \multicolumn{2}{|c|}{300} & \multicolumn{2}{|c|}{320} \\
\hline & $S$ & A & $S$ & A & $S$ & A & $\mathrm{S}$ & A & $S$ & A & $S$ & $\mathbf{A}$ & $S$ & A & $\mathrm{S}$ & A & $S$ & A \\
\hline 200 & 168 & 14.4 & 53 & 2.9 & & & & & & & & & & & & & & \\
\hline 400 & & & 176 & 15 & 17 & & & 1.6 & & & & & & & & & & \\
\hline 700 & & & & 28 & 28 & & & 2.7 & & & & & & & & & & \\
\hline 1000 & & & & & 41 & & 23 & 4.4 & & & & & & & & & & \\
\hline 1500 & & & & & & & 25 & 6.1 & & & & & & & & & & \\
\hline 2000 & & & & & & & 34 & 20 & & & & & & & & & & \\
\hline 2500 & & & & & & & 36 & & & & & & & & & & & \\
\hline 3000 & & & & & & & & & & & & & & & & & & \\
\hline 3500 & & & & & & & & & & & & & & & & & & \\
\hline 4000 & & & & & & & & & & & & & & & & & & \\
\hline 5000 & & & & & & & & & 34 & & 15 & & & & & & & \\
\hline 6000 & & & & & & & & & 26 & & 15 & & & & & & & \\
\hline 7000 & & & & & & & & & 25 & & 12 & 3.5 & & & & & & \\
\hline 8000 & & & & & & & & & & & 14 & 7.5 & 7 & & & & & \\
\hline 9000 & & & & & & & & & & & & & 9 & & & & & \\
\hline 10000 & & & & & & & & & & & & & 8 & & 2.5 & & 1 & 0.5 \\
\hline
\end{tabular}


TABLE IV

Periods of the oscillations in seconds in Sample 2 at different test temperatures and CO concentrations. Synthetic air (S) and ambient air (A) environments are indicated.

\begin{tabular}{|c|c|c|c|c|c|c|c|c|c|c|c|c|c|c|c|c|c|}
\hline \multirow{3}{*}{$\begin{array}{l}\text { Conc. } \\
\text { of CO } \\
\text { ppm }\end{array}$} & \multicolumn{17}{|c|}{ Test Temperature ${ }^{\circ} \mathrm{C}$} \\
\hline & \multicolumn{2}{|c|}{150} & \multicolumn{2}{|c|}{170} & \multicolumn{2}{|c|}{190} & \multicolumn{2}{|c|}{200} & \multicolumn{2}{|c|}{230} & \multicolumn{2}{|c|}{250} & \multicolumn{2}{|c|}{280} & 300 & \multicolumn{2}{|c|}{320} \\
\hline & S & A & $\mathrm{S}$ & A & S & A & $\mathrm{S}$ & A & $S$ & A & $S$ & A & S & A & $S * A$ & $S$ & A \\
\hline 200 & & & & & & & & & & & & & & & & & \\
\hline 400 & 60 & 11 & 60 & 5 & & & & & & & & & & & & & \\
\hline 700 & & & 50 & & & & & & & & & & & & & & \\
\hline 1000 & & & & & & & & 1 & & & & & & & & & \\
\hline 1500 & & & & & 21 & & 12 & 1.1 & & & & & & & & & \\
\hline 2000 & & & & & 26 & & 13 & 1.3 & & & & & & & & & \\
\hline 2500 & & & & & 30 & & 13 & 1.6 & & & & & & & & & \\
\hline 3000 & & & & & & & 18 & & & & & & & & & & \\
\hline 3500 & & & & & & & 20 & & & & & & & & & & \\
\hline 4000 & & & & & & & 30 & & & & & & & & & & \\
\hline 5000 & & & & & & & & & 38 & & & & & & & & \\
\hline 6000 & & & & & & & & & 18 & & & & & & & & \\
\hline 7000 & & & & & & & & & 14 & & 9 & 0.5 & & & & & \\
\hline 8000 & & & & & & & & & & & 11 & 0.8 & & & & & \\
\hline 9000 & & & & & & & & & & & & & 8 & & & & \\
\hline 10000 & & & & & & & & & & & & & 8 & & & & \\
\hline
\end{tabular}

The oscillatory responses to $\mathrm{CO}$ in air were different for sensors from different fabrication batches with different sintering temperature even if the compositions were the same. Within the same batch the results of both frequency and amplitude measurements between two sensors appeared to be similar with an accuracy of about $10 \%$.

The reproducibility of the repeated experiments on successive days was generally within $25 \%$.

\section{DISCUSSION}

The catalytic oxidation of $\mathrm{CO}$ on supported noble metal catalyst is characterized by dual dependence of reaction rate on $\mathrm{CO}$ concentration. This rate has a maximum value at a certain $\mathrm{CO}$ concentration, perhaps some percent of $\mathrm{CO}$ in $\mathrm{O}_{2}$. When $\mathrm{CO}$ concentration increases over that concentration the reaction order with respect to $\mathrm{CO}$ changes from positive to negative.

Oscillations can occur when the ratio of $\mathrm{CO}$ and oxygen concentrations is in the vicinity of that critical value.

According to E. McCarthy et $\mathrm{a}^{5}$ the rate $\mathrm{R}_{\mathrm{o}}$ of catalytic oxidation of $\mathrm{CO}$ on supported $\mathrm{Pt}$ catalyst can be described as follows:

$\mathrm{R}_{\mathrm{o}}=\frac{1}{1 / \mathrm{k}_{1}(\mathrm{CO})+(\mathrm{CO}) / \mathrm{k}_{2}}$

where $(\mathrm{CO})$ is the $\mathrm{CO}$ concentration,

$\mathrm{k}_{1}$ is the rate constant for the reaction $\mathrm{CO}+\mathrm{O}_{(\mathrm{a})} \rightarrow \mathrm{CO}_{2}$,

$\mathrm{k}_{2} \quad$ is the rate constant for the adsorption of oxygen and

$\mathrm{O}_{(\mathrm{a})}$ denotes the active chemisorbed form of oxygen on $\mathrm{Pt}$.

This expression shows the maximum as a function of $\mathrm{CO}$ concentration. It also includes two distinct rate constants that dominate at different $\mathrm{CO}$ concentrations so that the rate 
determining step of the overall reaction depends on $\mathrm{CO}$ concentration. Of the rate constants $\mathrm{k}_{1}$ can be sensitive to crystallite size of the catalyst metal.

The rate of $\mathrm{CO}$ oxidation on supported Pt catalyst at different temperatures as a function of $\mathrm{CO}$ concentration was determined by $\mathrm{E}$. McCarthy et $\mathrm{al}^{5}$. Their rate curves had maxima in the temperature range of $200^{\circ} \mathrm{C}-250^{\circ} \mathrm{C}$ approximately. This is comparable to the range in which oscillations were observed in this study, namely about $150^{\circ} \mathrm{C}-300^{\circ} \mathrm{C}$.

It has also been observed that the maximum value of the $\mathrm{CO}$ oxidation rate is obtained at a higher $\mathrm{CO}$ concentration when the substrate temperature becomes higher ${ }^{5,6,7}$. A similar effect was found in this study - the $\mathrm{CO}$ concentration ranges in which the oscillations occurred were higher at higher temperatures as shown in Figure 4.

In the oscillatory oxidation reaction of $\mathrm{CO}$ the adsorption and desorption steps can be critical. For example in the theory described above the dissociative adsorption of oxygen on noble metal catalyst is required to start the reaction. These adsorption and desorption steps can be influenced by other species adsorbed on the surface. In ambient air there is water vapour always present. The influence of water vapour can be the reason why the oscillations were quicker with $\mathrm{CO}$ in ambient air than with $\mathrm{CO}$ in synthetic air. Water vapour is known to increase the rate of $\mathrm{CO}$ oxidation on a solid catalyst. Water vapour also greatly enhances the sensitivity of semiconductor gas sensors to $\mathrm{CO}^{8}$.

A typical feature of sensors manufactured in this study was the variation of the oscillatory response to $\mathrm{CO}$ in frequency and amplitude and in some cases also in $\mathrm{CO}$ concentration where the oscillations appeared between different batches. This could be attributed to different particle and surface structures of the Pd catalyst. The difference in the oscillation frequency, for instance, was very clear between sensors sintered at different peak temperatures which were $600^{\circ} \mathrm{C}$ and $850^{\circ} \mathrm{C}$.

How the oscillatory oxidation of $\mathrm{CO}$ by hetereogeneous catalysis on sensor surface manifests itself as the oscillation of conductivity of the $\mathrm{SnO}_{2}$ base material has not yet been unambiguously explained. In the present study of current oscillations the sharp decline of the current pulse and the quick onset of the current increase appear to be salient features. They mean quick decrease and increase in sensor conductance.

It has been suggested that the conductance oscillations could be due to the variation of temperature caused by the catalytic reaction. In the context of the oscillatory catalytic oxidation reaction of $\mathrm{CO}$ the thermal nature of the conductance variation must be excluded because this oxidation reaction has been pointed out to be isothermal under relevant conditions $^{5,9}$.

The rapid changes observed in the conductance cannot be explained by any slow process like electron transfer between surface species at particle boundaries and the material. Such transfers can change the conductivity by changing the heights of the energy barriers caused by surface charges at boundary surfaces between particles. But these charge transfer processes are much too slow at the test temperatures used in this study.

The barrier energies and consequently the conductance could, however, be changed even quickly by changes in the donor concentration of the $\mathrm{SnO}_{2}$ material. The donor concentration could in turn be affected by changes in the stoichiometry due to oxidation or reduction reactions. Yet the quick oxidation of the $\mathrm{SnO}_{2}$ surface by oxygen adsorbed directly from the atmosphere is not expected to happen, because this type of oxidation of the surface of $\mathrm{SnO}_{2}$ has been found to be a slow process ${ }^{10}$.

One explanation for the quick decrease of the conductance could be the fast oxidation of the surface caused by dissociated active oxygen. This form of oxygen could be formed in a spill-over reaction over Pd (or any other noble metal) catalyst. After this step the oxidation of $\mathrm{CO}$ would start rapidly and result in the formation of $\mathrm{CO}_{2}$ residing adsorbed at the surface. The reacting $\mathrm{CO}$ would partly reduce the $\mathrm{SnO}_{2}$ surface. After the initial stage the rate of the $\mathrm{CO}$ oxidation reaction would decrease, as seen in Figure 1. When the saturation condition of surface $\mathrm{CO}_{2}$ is reached quick desorption of $\mathrm{CO}_{2}$ would happen giving way to a fast reoxidation step. 
That the dissociated form of oxygen plays a role in the oscillation process has been demonstrated by quickly dropping the temperature of $\mathrm{SnO}_{2}$ gas sensors from $380^{\circ} \mathrm{C}$ to $125^{\circ} \mathrm{C}^{11}$. These sensors did not contain any noble metal catalyst. After the drop in temperature current oscillations appeared at $125^{\circ} \mathrm{C}$ and decayed away slowly. This thermal treatment is believed to leave dissociated oxygen ions $\left(\mathrm{O}^{-}\right)$formed on the surface at $380^{\circ} \mathrm{C}$ even at $125^{\circ} \mathrm{C}$. This dissociated form of oxygen slowly vanishes which manifests itself as the slow decay of the oscillation.

Gases other than $\mathrm{CO}$ which show oscillatory behaviour include hydrogen and ammonia. According to Kanefusa et $\mathrm{al}^{2}$ these oscillations occur around temperatures of $90^{\circ} \mathrm{C}\left(\mathrm{H}_{2}\right)$ and $370^{\circ} \mathrm{C}\left(\mathrm{NH}_{3}\right)$ which are outside the range of oscillations due to $\mathrm{CO}$. As the sensor compositions were also different in both these cases there should be no interference by these gases when $\mathrm{CO}$ is being sensed using this technique.

\section{CONCLUSIONS}

Conductance oscillations in the presence of $\mathrm{CO}$ were observed in sensors containing $\mathrm{Pd}$ at temperatures between $150^{\circ} \mathrm{C}$ and $320^{\circ} \mathrm{C}$. The range of $\mathrm{CO}$ concentration in which conductance oscillations occurred increased with increasing test temperature. At the lowest the concentration range was around $200 \mathrm{ppm} \mathrm{CO}$ and at the highest from 8000 to $10000 \mathrm{ppm}$. By controlling the sensor operating temperature different ranges of $\mathrm{CO}$ concentration could be utilized for detection.

The presence of water vapour seems to make oscillations rapid and clear. Even if it changes the frequency of oscillations the concentration ranges of the occurrence of oscillations seem to remain roughly the same.

Due to the statistical nature of the oscillations the surface and particle structure of the catalytic additive is probably critical. This means strict control of processing conditions is essential. On the other hand it allows the control of the sensing properties like the concentration range and oscillation frequency.

$\mathrm{CO}$ sensors utilizing the conductance oscillation phenomenon might find use, for example, in threshold value indicators or alarm systems. Better understanding of the phenomenon and control of fabrication and operation conditions could lead to feasible use of this type of sensor for more exact measurements. The specificity of the phenomenon seems to indicate that it is possible to obtain good selectivity under appropriate conditions.

\section{ACKNOWLEDGEMENTS}

The work was supported by the Finnish Technical Development Centre, and Finnish companies Neste Ltd., Outokumpu Ltd. and Vaisala Ltd. Special thanks are extended to Professor Seppo Leppävuori for encouraging this study.

\section{REFERENCES}

1. M. Nitta and M. Haradome, "Oscillation phenomenon in thick-film CO sensor", IEEE Trans. Electron Devices, $E D-26,219$ (1979).

2. S. Kanefusa, M. Nitta and M. Haradome, "Oscillation phenomenon in a $\mathrm{SnO}_{2}$-based gas sensor", Proc. Int. Meeting on Chemical Sensors, Fukuoka, Japan, 84 (1983).

3. A. Accorsi and J. Bernard, "Resistivity oscillation during catalytic oxidation of carbon monoxide on $\mathrm{Pt} / \mathrm{SnO}_{2}$ ", Proc. 2nd Int. Meeting on Chemical Sensors, Bordeaux, France, 205 (1986).

4. P. Romppainen, H. Torvela, J. Väänänen and S. Leppävuori, "Effect of $\mathrm{CH}_{4}, \mathrm{SO}_{2}$ and $\mathrm{NO}$ on the $\mathrm{CO}$ response of an $\mathrm{SnO}_{2}$-based thick film gas sensor in combustion gases", Sensors and Actuators, 8, 271 (1985).

5. E. McCarthy, J. Zahradnik, G.C. Kuczynski and J.J. Carberry, "Some unique aspects of CO oxidation on supported Pt", J. Catal., 39, 29 (1975).

6. J.P. Dauchot and J. Van Cakenberghe, "Oscillatory catalytic oxidation of carbon monoxide on a 
Schottky-diode", Japanese J. Appl. Phys., Suppl. 2, Part 2, 533 (1974).

7. T. Matsushima, "The mechanism of the CO oxidation over polycrystalline platinum", Bull. Chem. Soc. Japan, $51,1956(1978)$

8. P.K. Clifford, "Mechanisms of gas detection by metal oxide surfaces", PhD dissertation, Carnegie-Mellon University, Pittsburgh, USA (1981).

9. J.J. Carberry and A.A. Kulkarni, "The non-isothermal catalytic effectiveness factor for monolith supported catalysts", J. Catal., 31, 41 (1973).

10. M.J. Fuller and M.E. Warwick, "The catalytic oxidation of carbon monoxide on tin (IV) oxide", J. Catal., 29, 441 (1973).

11. V. Lantto and P. Romppainen, "Electrical studies on the reactions of $\mathrm{CO}$ with different oxygen species on $\mathrm{SnO}_{2}$ surfaces", submitted for publication in Surface Science (1987). 

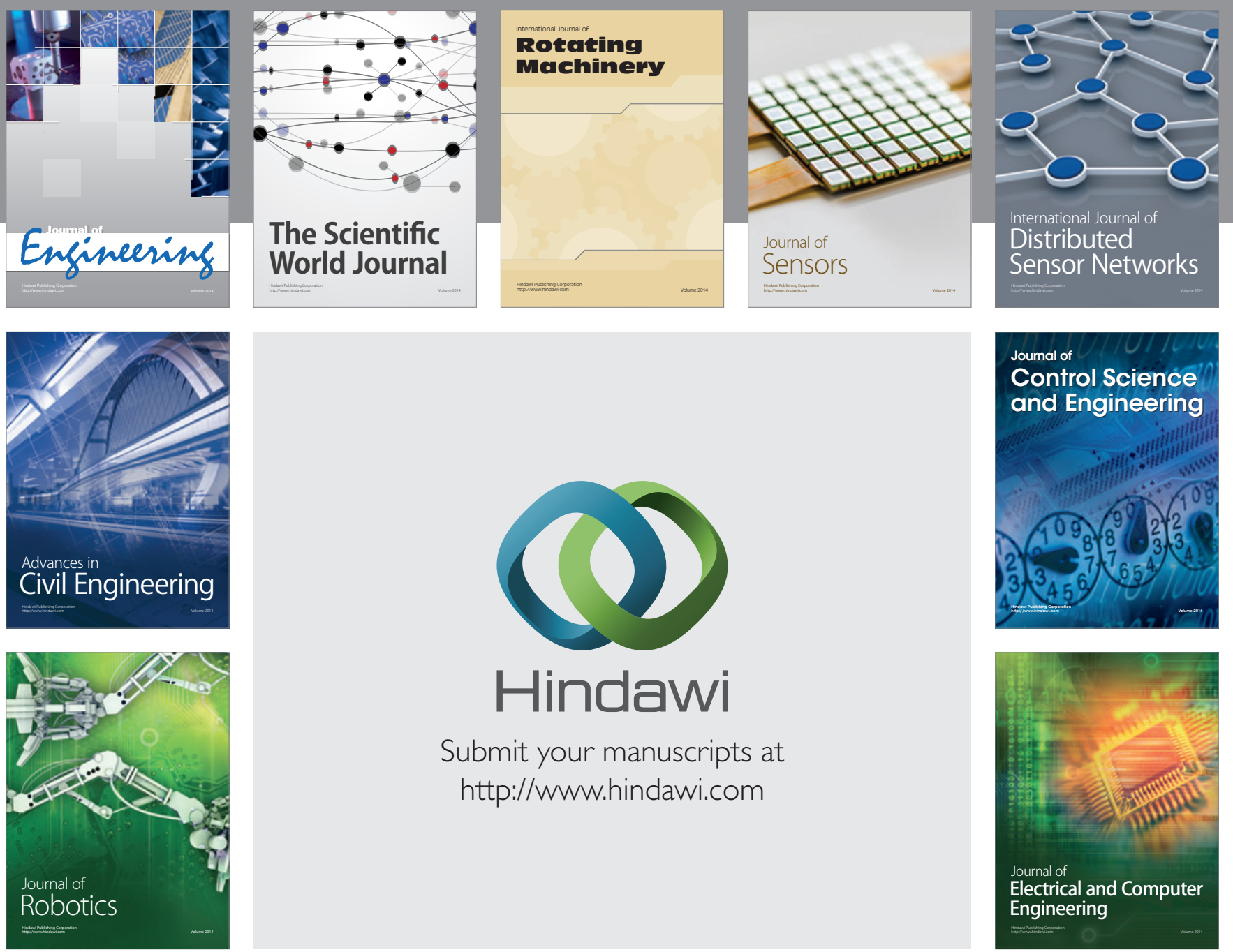

Submit your manuscripts at

http://www.hindawi.com
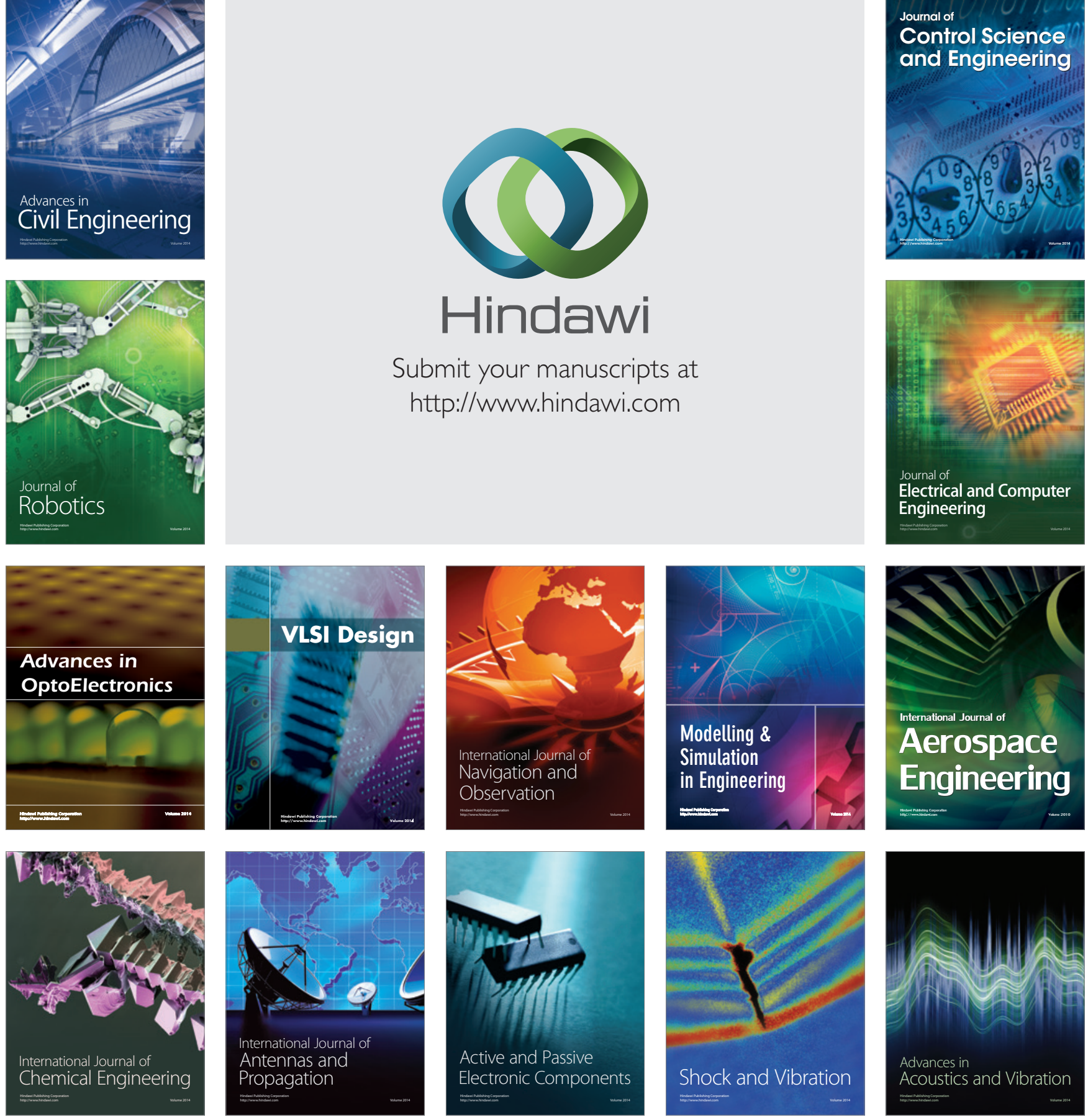